\title{
SINTERIZAÇÃO DO NIÓBIO: EFEITO DA GRANULOMETRIA DOS PÓS
}

\author{
Guilherme Souza Leite ${ }^{1}$ \\ Hugo Ricardo Zschommler Sandim ${ }^{2}$ \\ Osvaldo Mitsuyuki Cintho ${ }^{3}$
}

\section{Resumo}

São caracterizadas as microestruturas obtidas a partir da sinterização de pós de nióbio com cinco granulometrias distintas. Amostras prensadas uniaxialmente a frio foram sinterizadas em alto vácuo em $1.900^{\circ} \mathrm{C}$ e $2.000^{\circ} \mathrm{C}$, por diversos tempos. Os efeitos causados pela granulometria dos pós foram analisados por meio da determinação da fração volumétrica de poros e do tamanho de grão no sinterizado. As curvas de densificação mostram a diminuição da porosidade média das amostras até a estabilização em aproximadamente $3,0 \%$ para as amostras com as granulometrias $-200+270 \#$ e $-635 \#$ (em mesh). Os resultados apresentam boa concordância com a literatura acerca da metalurgia do pó.

Palavras-chave: Nióbio; Metalurgia do pó; Sinterização; Caracterização microestrutural.

\section{SINTERING OF NIOBIUM: EFFECT OF POWDER PARTICLE SIZE}

\begin{abstract}
Microestructural characterization of sintered niobium obtained by solid-state sintering of powders with distinct granulometries was performed. The influence of using powders with different particle sizes was analyzed by determining both the volume fraction of pores and grain size after sintering at $1900^{\circ} \mathrm{C}$ and $2000^{\circ} \mathrm{C}$ for distinct holding times. The densification curves show the decrease of the porosity which levels off at about $3.0 \%$ for samples made with the powder sizes $-200+270 \#$ and $-635 \#$ (mesh). The results are in good agreement with those reported in the literature.
\end{abstract}

Key words: Niobium; Powder metallurgy; Sintering; Microstructural characterization.

\section{INTRODUÇÃO}

O nióbio é um metal refratário com estrutura cúbica de corpo centrado, macio e dúctil, dependendo do teor total de impurezas intersticiais $(\mathrm{C}+\mathrm{N}+\mathrm{O}+\mathrm{H})$. As maiores reservas deste metal encontram-se no Brasil (98\%), de modo que o estudo de novas aplicações deste metal tem caráter estratégico para o País. ${ }^{(1,2)}$

Somente em 1944, pó de nióbio foi compactado em barras e sinterizado em forno resistivo de alto vácuo pela primeira vez, mas não há muitos detalhes sobre os parâmetros desse processo. Desde então, pesquisas sobre o processo de metalurgia do pó do nióbio puro são ainda limitadas em número. ${ }^{(3)}$

A produção de nióbio sinterizado via metalurgia do pó inclui a compactação e a posterior sinterização em alto vácuo. ${ }^{(4-6)} A$ técnica denominada $\mathrm{HDH}$ (hidrogenaç̧ão-desidrogenação) é uma das técnicas mais utilizadas para a produção de pós. Ela consiste na formação de hidretos frágeis nos pós, que após moagem, são desgaseificados em alto vácuo $\left(\mathrm{P}<10^{-4} \mathrm{mbar}\right)$. Os pós obtidos possuem baixos teores de hidrogênio, podendo ser facilmente classificados, compactados a frio e posteriormente densificados via sinterização no estado sólido. ${ }^{(7,8)}$

Uma das mais promissoras aplicações do nióbio processado via metalurgia do pó $(\mathrm{P} / \mathrm{M})$ é $\mathrm{o}$ uso em implantes cirúrgicos..$^{(4)}$ Os materiais metálicos porosos biocompatíveis possuem uma superfície específica elevada que favorece a interação do implante com o osso.(9)

A porosidade de um material varia, de um modo geral, com a temperatura e o tempo de sinterização. A sinterização em altas temperaturas $\left(\sim 2.000^{\circ} \mathrm{C}\right)$ sob alto vácuo promove a densificação do nióbio. ${ }^{(3,4)}$ Desse modo, a porosidade poderia ser controlada de modo a assegurar uma superfície específica elevada para facilitar a etapa de osteointegração. Numa segunda etapa, o uso

\footnotetext{
' Graduando, Escola de Engenharia de Lorena, Universidade de São Paulo, Polo Urbo-Industrial Gleba Al-6, CP I I6, Cep I2600-970, Lorena, SP, Brasil. E-mail: guilherme.leite@alunos.eel.usp.br

2 Professor Associado, Departamento de Engenharia de Materiais, Escola de Engenharia de Lorena, Universidade de São Paulo, Polo Urbo-Industrial Gleba Al-6, CP I 16, Cep 12600-970, Lorena, SP, Brasil. E-mail: hsandim@demar.eel.usp.br

${ }_{3}^{3}$ Professor Associado, Departamento de Engenharia de Materiais, Universidade Estadual de Ponta Grossa, Av. Gal. Carlos Cavalcante, 4748, Bloco L, Uvaranas, Cep 84030-000, Ponta Grossa, PR, Brasil. E-mail: omcintho@uepg.br
} 
de espaçadores poderia levar à formação de estruturas altamente porosas $\left(V_{p}>0,5\right)$ com poros cujo tamanho e espaçamento podem ser controlados. Parâmetros microestruturais relevantes podem ser quantificados por meio de técnicas estereológicas. ${ }^{(10)}$ De um modo relativamente simples, via análise metalográfica de seções planas, é possível quantificar a fração volumétrica de uma dada fase por meio da determinação da fração de pontos numa seção plana. O resultado depende do uso de microscópios, softwares e grades de pontos adequados para cada escala de tamanho desejada após cuidadosa preparação metalográfica. ${ }^{(11,12)}$

A interpretação correta das características das microestruturas presentes nos materiais produzidos via $\mathrm{P} / \mathrm{M}$ é um desafio. A própria determinação da porosidade do material é uma tarefa complicada. Situado no interior e na superfície do material, os poros são formados pelo rearranjo das partículas do material. Independentemente da forma, uma avaliação cuidadosa da microestrutura é impossível sem a exata representação da estrutura dos poros. Tamanho, forma, distribuição e tipo de poro (aberto ou fechado) são características importantes a serem determinadas. ${ }^{(13-15)}$ Dificuldades comuns na determinação da fração de poros incluem $\circ$ preenchimento dos poros do material com impurezas ou com o próprio material e a seletividade e a reatividade ao ataque metalográfico. ${ }^{(12)}$

No presente trabalho, pós de nióbio com cinco granulometrias distintas foram compactados a frio e sinterizados em alto vácuo. É investigada a influência da fração granulométrica dos pós de partida na porosidade final e no tamanho de grão com o uso de técnicas de metalografia quantitativa em amostras digitalizadas a partir de um microscópio óptico.

\section{MATERIAL E MÉTODOS}

Pós de nióbio obtidos pelo método HDH foram processados no Departamento de Engenharia de Materiais da Escola de Engenharia de Lorena (DEMAR-EEL-USP) em cinco granulometrias distintas. As granulometrias escolhidas foram as seguintes: $-200+270 \#,-270+325 \#$, $-325+500 \#,-500+635 \#$ e $-635 \#$ (em mesh). A composição química dos referidos pós em termos dos intersticiais encontra-se na Tabela I. A análise da distribuição do

Tabela I. Teor de elementos intersticiais nas cinco frações investigadas

\begin{tabular}{cccc}
\hline \multirow{2}{*}{ Fração } & \multicolumn{3}{c}{ Teor em ppm-p } \\
\cline { 2 - 4 } & $\mathbf{C}$ & $\mathbf{N}$ & $\mathbf{O}$ \\
\hline$-200+270$ & 49 & 1.236 & 3.097 \\
$-270+325$ & 62 & 1.743 & 4.534 \\
$-325+500$ & 85 & 2.426 & 4.013 \\
$-500+635$ & 103 & 2.241 & 5.994 \\
-635 & - & 2.355 & 6.662 \\
\hline
\end{tabular}

tamanho de partículas nos pós foi feita com o auxilio de um analisador CILAS 1064 em meio líquido e com dispersante. Os tamanhos médios das partículas (para $50 \%$ de retenção) para as frações $-200+270 \#$ e $-635 \#$ foram determinados e são iguais a $74 \mu \mathrm{m}$ e $13 \mu \mathrm{m}$, respectivamente. Pastilhas cilíndricas foram prensadas uniaxialmente a frio em pressões de $1.500 \mathrm{MPa}$. As dimensões típicas dos corpos a verde são diâmetro de $8 \mathrm{~mm}$ e altura de $2,5 \mathrm{~mm}$.

A sinterização das amostras de pós de nióbio compactados foi realizada em um formo bipolar resistivo em alto vácuo $\left(\mathrm{P}<10^{-5} \mathrm{mbar}\right)$ utilizando-se elementos resistivos de tântalo em temperaturas de $1.900^{\circ} \mathrm{C}$ durante I h e em $2.000^{\circ} \mathrm{C}$, para os tempos de $5 \mathrm{~min}, 15 \mathrm{~min}, 30 \mathrm{~min}$, $60 \mathrm{~min}, 120 \mathrm{~min}, 240 \mathrm{~min} \mathrm{e} 480 \mathrm{~min}$. Antes e após a sinterização, a altura, o diâmetro e a massa de cada amostra foram medidos com o auxilio de micrômetro digital e balança de precisão. As amostras de nióbio foram preparadas metalograficamente seguindo os padrões convencionais de metalografia: corte, embutimento, lixamento, polimento e ataque químico.(II) Após a preparação metalográfica, as amostras foram digitalizadas com o auxílio de um microscópio óptico Leica modelo DM IRM com câmera Samsung modelo SCC I3| acoplado a um analisador de imagens Leica Qwin. Para a determinação da fração volumétrica de poros, as imagens foram digitalizadas e superpostas a uma rede quadriculada com $55 \mathrm{I}$ pontos (29 $\times 19$ linhas). A fração de pontos $\left(P_{P}\right)$ é igual à fração volumétrica $\left(V_{v}\right)$ e é definida como sendo a razão entre o número total de interceptos (número de pontos que incide sobre os poros) pelo numero total de pontos da grade. O tamanho médio de grão foi determinado a partir do método do intercepto linear. A preparação metalográfica das amostras de nióbio foi feita seguindo os padrões reportados na literatura. ${ }^{(I I)}$ Os melhores resultados são aqueles que utilizaram no polimento uma suspensão coloidal OP-S (Struers), $40 \mathrm{~mL}$ de $\mathrm{H}_{2} \mathrm{O}_{2} 30 \%, \mathrm{I}, 5 \mathrm{~mL}$ de $\mathrm{HNO}_{3}, \mathrm{I}, 0 \mathrm{~mL}$ de $\mathrm{HF}$, diluída em água. $\mathrm{O}$ ataque químico usou uma solução com composição $50 \mathrm{~mL}$ de $\mathrm{H}_{2} \mathrm{O}, 20 \mathrm{~mL}$ de $\mathrm{HNO}_{3}$ e $15 \mathrm{~mL}$ de $\mathrm{HF}$ com tempo de imersão variando de $30 \mathrm{~s}$ a $40 \mathrm{~s}$. Sob estas condições, tanto os poros como os contornos de grão são revelados. Condições mais severas de ataque metalográfico causam o alargamento dos poros devido ao ataque seletivo destas estruturas.

\section{RESULTADOS}

Os resultados da caracterização dos compactos a verde das amostras obtidas a partir dos pós com diferentes granulometrias são apresentados na Tabela 2. A Figura I mostra a cinética de densificação das amostras sinterizadas em vácuo na temperatura de $2.000^{\circ} \mathrm{C}$ obtidas a partir da prensagem de pós com duas faixas granulométricas distintas $(-200+270 \#$ e $-635 \#)$.

No caso dos resultados apresentados da Tabela 2 , deve-se ressaltar que as amostras foram prensadas sob elevadas pressões de compactação (I.500 MPa), daí os 
Tabela 2. Massa específica e porosidade inicial dos compactos a verde em função da granulometria

\begin{tabular}{lcccccc}
\hline \multicolumn{1}{c}{ Amostras } & $\mathbf{- 2 0 0 + 2 7 0 \#}$ & $\mathbf{- 2 7 0 + 3 2 5 \#}$ & $\mathbf{- 3 2 5 + 5 0 0 \#}$ & $\mathbf{- 5 0 0 + 6 3 5 \#}$ & $\mathbf{- 6 3 5 \#}$ \\
\hline Abertura da peneira $(\mu \mathrm{m})$ & 74 & 53 & 44 & 27 & 13 \\
Massa específica $\left(\mathrm{g} / \mathrm{cm}^{3}\right)$ & $8,14 \pm 0,20$ & $8,07 \pm 0,20$ & $8,05 \pm 0,20$ & $7,84 \pm 0,20$ & $7,70 \pm 0,20$ \\
Massa específica relativa $(\%)$ & $95,0 \pm 1,0$ & $94,2 \pm 1,0$ & $93,9 \pm 1,0$ & $91,5 \pm 1,0$ & $89,9 \pm 1,0$ \\
Porosidade (\%) & $5,0 \pm 1,0$ & $5,9 \pm 1,0$ & $6,1 \pm 1,0$ & $8,5 \pm 1,0$ & $10,1 \pm 1,0$ \\
\hline
\end{tabular}

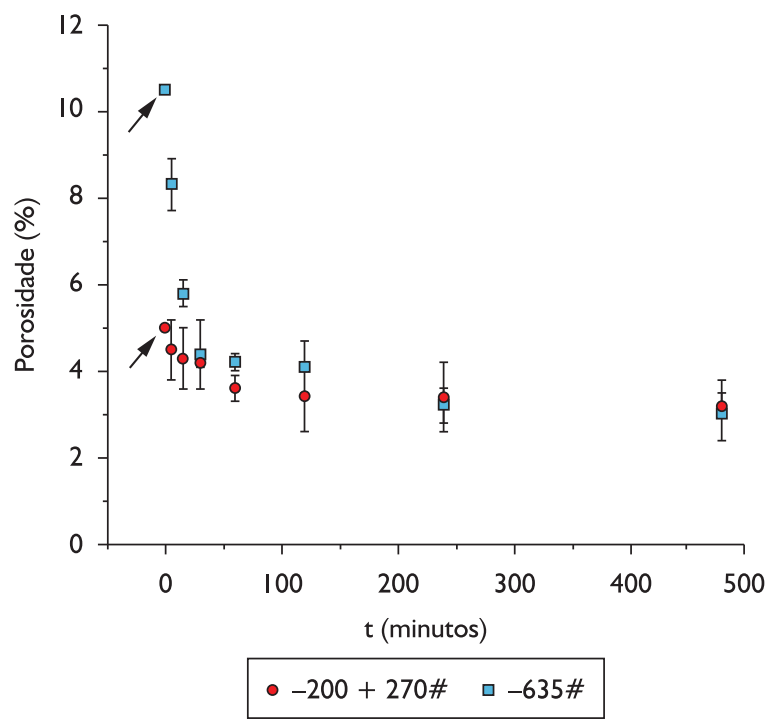

Figura I. Cinética de densificação das amostras de nióbio sinterizadas em $2.000^{\circ} \mathrm{C}$. As setas indicam a porosidade inicial das amostras para cada granulometria (compactos a verde).

elevados valores da massa específica a verde (material de partida), superiores a $85 \%$ da massa específica teórica do nióbio. A densidade relativa $\left(D_{R}\right)$ também foi calculada a partir da relação $D_{R}=D / D_{T}$, onde $D$ é a massa específica dos compactos a verde e $D_{T}$ é a massa específica do nióbio $\left(8,57 \mathrm{~g} / \mathrm{cm}^{3}\right)$.

O engrossamento microestrutural é um aspecto importante a ser avaliado na sinterização do nióbio em altas temperaturas. Além da desejada redução da porosidade, o crescimento de grão ocorre para tempos mais longos e temperaturas de sinterização mais elevadas. Neste sentido, determinou-se o tamanho médio de grão das amostras sinterizadas em $1.900^{\circ} \mathrm{C}$ e em $2.000^{\circ} \mathrm{C}$, para um tempo de sinterização (patamar) de I h para as cinco frações utilizadas. Os resultados são mostrados na Tabela 3. Imagens representativas das amostras sinteri- zadas com diferentes pós foram obtidas via microscopia óptica. A Figura 2 mostra a microestrutura das amostras sinterizadas em $1.900^{\circ} \mathrm{C}$ e em $2.000^{\circ} \mathrm{C}$ por I h nas cinco faixas granulométricas utilizadas.

\section{DISCUSSÃO}

Os resultados mostram que pós mais finos apresentam menor massa específica a verde do que aqueles prensados a partir de pós mais grosseiros. Isso se deve ao atrito causado pela maior área de contato entre as partículas. ${ }^{(13)}$ Sob pressões de compactação próximas a $200 \mathrm{MPa}$, a massa específica a verde da fração $-635 \#$ é de $65 \%$ da massa específica teórica do nióbio. ${ }^{(4)}$ No caso das amostras investigadas neste trabalho (Tabela I), pressões muito maiores foram aplicadas levando à obtenção de corpos verdes muito mais densos (cerca de $90 \%$ da massa específica teórica do nióbio).

A cinética de densificação a $2.000^{\circ} \mathrm{C}$ do nióbio nas granulometrias $-200+270 \#$ e $-635 \#$ é mostrada na Figura I. Nota-se que as amostras possuem diferentes porosidades iniciais. Além disso, a contração observada na fração -635\# é muito maior que a encontrada na fração $-200+270 \#$. A partir de I h de sinterização, nesta temperatura, a porosidade final se estabiliza em torno de 3,0\% para as duas granulometrias estudadas.

Os resultados da caracterização microestrutural das amostras sinterizadas são mostrados na Figura 2. A análise metalográfica quantitativa das amostras sinterizadas em $1.900^{\circ} \mathrm{C}$ e $2.000^{\circ} \mathrm{C}$ por I $\mathrm{h}$ indica que as amostras apresentam porosidades distintas. A porosidade final aumenta à medida que $\circ$ tamanho dos pós diminui, ou seja, a porosidade é maior na amostra de -635\#. Além disso, as amostras sinterizadas a $2.000^{\circ} \mathrm{C}$ por I $\mathrm{h}$ possuem uma porosidade menor que as sinterizadas a $1.900^{\circ} \mathrm{C}$. Em contrapartida, o tamanho de grão nas amostras sinterizadas a $2.000^{\circ} \mathrm{C}$ é maior do que as amostras sinterizadas a $1.900^{\circ} \mathrm{C}$.

Tabela 3. Tamanho médio de grão das amostras sinterizadas em $1.900^{\circ} \mathrm{C}$ e $2.000^{\circ} \mathrm{C}$

\begin{tabular}{cccccc}
\hline Tamanho de grão $(\mu \mathrm{m})$ & $-200+270 \#$ & $-270+325 \#$ & $-325+500 \#$ & $-500+635 \#$ & $-635 \#$ \\
\hline $1.900^{\circ} \mathrm{C} / \mathrm{I} \mathrm{h}$ & $82 \pm 15$ & $77 \pm 14$ & $67 \pm 13$ & $55 \pm 9$ & $54 \pm 1 \mathrm{I}$ \\
$2.000^{\circ} \mathrm{C} / \mathrm{I} \mathrm{h}$ & $204 \pm 32$ & $187 \pm 29$ & $164 \pm 30$ & $157 \pm 22$ & $154 \pm 24$ \\
\hline
\end{tabular}




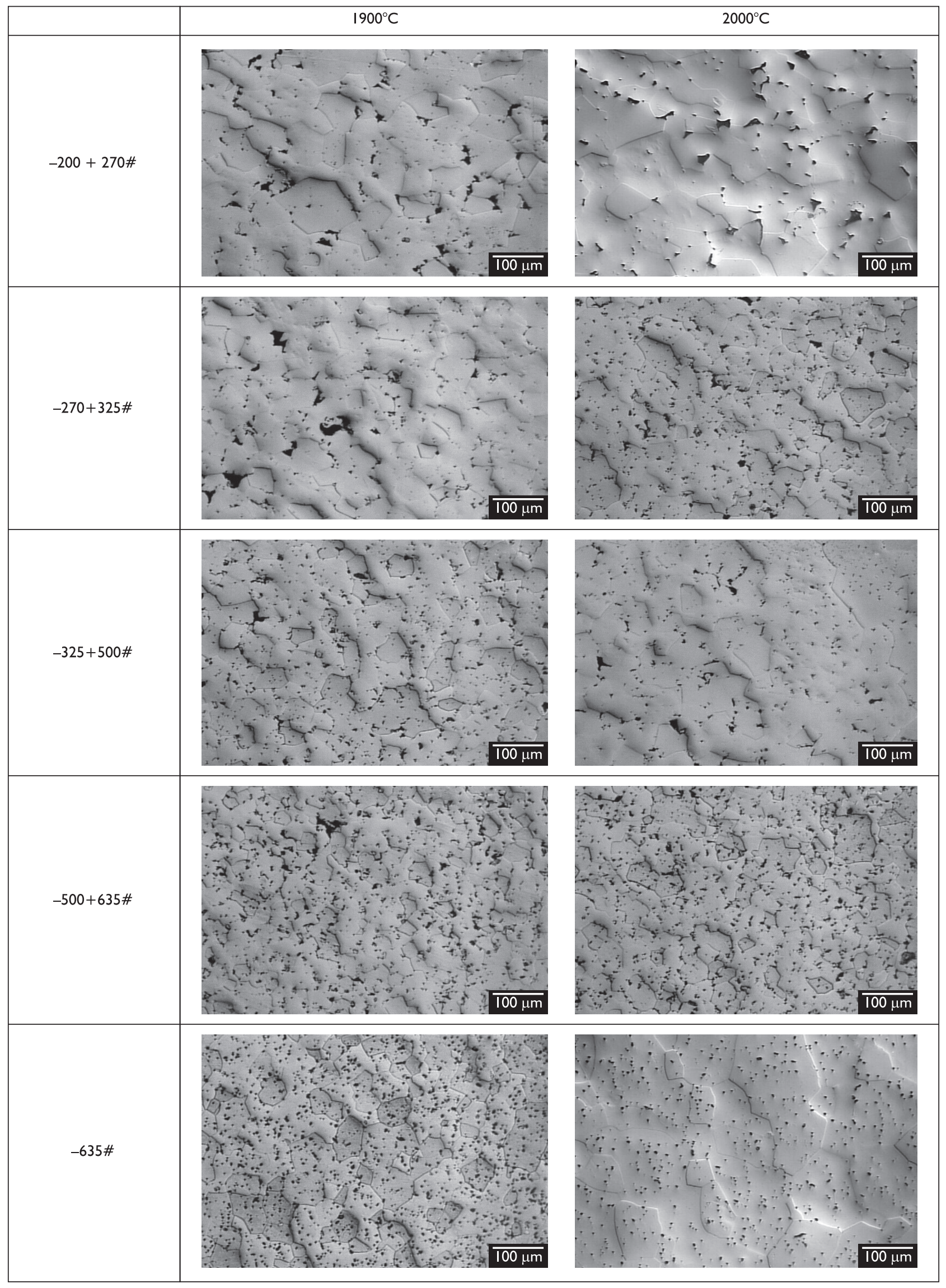

Figura 2. Micrografias das amostras sinterizadas a $1.900^{\circ} \mathrm{C}$ e $2.000^{\circ} \mathrm{C}$ por I h para as diferentes frações granulométricas utilizadas. 
Um aspecto importante a ser discutido é a mudança da morfologia dos poros, que também varia com a granulometria dos pós. No caso dos pós mais finos, os poros são menores, mais esféricos e isolados. Já nas amostras processadas com pós mais grosseiros, os poros são maiores (menores em número) e interconectados.

Observa-se também que o tamanho de grão no nióbio sinterizado diminui quando os pós se tornam mais finos. A sinterabilidade de um pó depende, dentre outros fatores, do tamanho médio e da rugosidade superficial das partículas. ${ }^{(13)}$ As duas frações granulométricas investigadas possuem tamanhos médios de partículas distintos. Em comum, ambas as frações possuem partículas com morfologia angular, típica de pós processados a partir da técnica $\mathrm{HDH}$ (hidretação-dehidretação). No caso das amostras sinterizadas em $1.900^{\circ} \mathrm{C}$ por I $\mathrm{h}$, o tamanho médio de grão da fração $-200+270 \#$ é de $82 \pm 15 \mu \mathrm{m}$. Para o pó mais fino, este valor cai para $54 \pm \mathrm{I} \mathrm{I} \mu \mathrm{m}$.

Admitindo-se que o tamanho médio inicial das partículas dos pós de nióbio nas frações $-200+270 \#$ e $-635 \#$ seja igual ao tamanho de grão inicial $(74 \mu \mathrm{m}$ e I $3 \mu \mathrm{m}$, respectivamente), nota-se que o tamanho médio do grão sinterizado varia muito pouco para a fração $-200+270$ \# e quase triplica para a fração -635 \# para I h de sinterização a $1.900^{\circ} \mathrm{C}$. As diferenças são ainda maiores a $2000^{\circ} \mathrm{C}$. Isso pode ser explicado pelo fato de que o crescimento de grão tem como força-motriz a redução da área interfacial dos contornos de grão. Com a elevação da temperatura de sinterização $\left(2.000^{\circ} \mathrm{C}\right)$, a maior ativação térmica leva à ocorrência de crescimento de grão nas duas frações investigadas, porém com intensidades distintas, corroborando os dados recentes na literatura. (3) Nota-se, ainda, que o tamanho de grão final da fração mais grosseira é maior que o observado nas amostras sinterizadas a partir do pó mais fino. Uma possível explicação para tal fato é a maior interação entre os contornos de grão e os poros nas duas amostras. Apesar de as duas amostras apresentarem porosidades finais próximas, o número total de poros na amostra -635\# é maior que o encontrado na fração $-200+270 \#$. Poros mais finos e menos espaçados exercem uma força retardadora (Zener pinning) mais eficiente para retardar a migração dos contornos de grão do que no caso de poros mais grosseiros e mais espaçados na matriz.

\section{CONCLUSÃo}

Amostras de nióbio foram sinterizadas em alto vácuo em duas temperaturas $\left(1.900^{\circ} \mathrm{C}\right.$ e $\left.2.000^{\circ} \mathrm{C}\right)$ a partir de pós com cinco distintas granulometrias. Medidas de metalografia quantitativa permitem quantificar a porosidade e o tamanho de grão após cada etapa de sinterização. A partir destes resultados é possível determinar a cinética de densificação de duas frações granulométricas distintas em $2.000^{\circ} \mathrm{C}$.

A porosidade final das amostras sinterizadas em $2.000^{\circ} \mathrm{C}$ é de aproximadamente $3,0 \%$. Observa-se crescimento de grão nas amostras sinterizadas em $1.900^{\circ} \mathrm{C}$ e $2.000^{\circ} \mathrm{C}$ por I h. A amostra processada com o pó mais fino (-635\#) apresenta maior cinética de densificação que a do pó mais grosseiro $(-200+270 \#)$; entretanto, o tamanho de grão final é maior na fração mais grosseira após sinterização em $2.000^{\circ} \mathrm{C}$ por I h. Além de terem sido processadas a partir de pós com diferentes frações granulométricas, a maior interação poro-contorno explica porque os grãos cresceram menos quando a fração mais fina foi utilizada.

\section{Agradecimentos}

Os autores agradecem ao Conselho Nacional de Desenvolvimento Científico e Tecnológico (CNPq) pelo auxílio financeiro de bolsa de Iniciação Científica.

\section{REFERÊNCIAS}

I LAVERICK, C. Niobium demand and superconductor applications: an overview. Journal of Less-Common Metals, v. I39, n. I, p. 107-22, Apr. 1988. http://dx.doi.org/10.1016/0022-5088(88)90334-7

2 REFRACTORY metals and alloys. In: ASM Handbook. I0. ed. Metals handbook. Metals Park: ASM International, I993. P. 557-83.

3 AGGARWAL, G. et al. Development of niobium powder injection molding: Part II. Debinding and sintering. International Journal of Refractory Metals and Hard Materials, v. 25, n. 3, p.226-36, May 2007. http://dx.doi.org/l0.1016/j. ijrmhm.2006.05.005

4 SANDIM, H. R. Z.; PADILHA, A. F. Powder metallurgy processing of Nb-TiO2 materials. International Journal of Powder Metallurgy, v. 34, n. 2, p. 34-4I, Ago. 1998.

5 SANDIM, H. R. Z et al. Electrical resistive of an oxide dispersion strengthened niobium alloy (Nb-0.5 wt\%TiO2-ODS). International Journal of Refractory Metals and Hard Materials, v. I6, n. 2, p. I43-I47, Nov. I998. http://dx.doi. org/I0.1016/S0263-4368(98)00027-4

6 SANDIM, H. R. Z.; PADILHA, A. F. On the sinterability of commercial-purity niobium. Key Engineering Materials, v. I89, n. I, p. 296-30I, Nov. 200 I. http://dx.doi.org/I0.4028/www.scientific.net/KEM. I89-I9I.296 
7 CANDIOTO, K. C. G.; NUNES, C. A. Nb-20\%Ta alloy powder by the hydriding-dehydriding technique. International Journal of Refractory Metals and Hard Materials, v.24, n. 6, p.4I3-7, Jun. 2006. http://dx.doi.org/10.1016/j. ijrmhm.2005.06.00I

8 GOMES, U. U. et al. Sintering of $\mathrm{Nb}$-Ta powders from aluminothermic reduction product (ATR). International Journal of Refractory Metals and Hard Materials, v. I I, n. I, p. 43-7, Feb. 1992. http://dx.doi.org/I0. I016/0263-4368(92)90083-E

9 RODRIGUES, M. R. B. Reconstrução microestrutural 3D das ligas Ti-6V-4V e Nb-TiO2 por seccionamento em série. 2009. 100 p. Tese (Doutorado) - Escola de Engenharia Industrial Metalúrgica de Volta Redonda da Universidade Federal Fluminense, Volta Redonda, 2009.

I0 PADILHA, A. F. Materiais de engenharia. Curitiba: Hemus, 2000.

I I MCCALL, J.L. A review of metallographic preparation procedures for niobium and niobium alloys. In: CONFERENCE NIOBIUM I984, New York. Proceedings... São Francisco, EUA: AIME, 1984. p. 4I7-4I.

I2 LAWLEY, A.; MURPHY, T. F. Metallography of powder metallurgy materials. Materials Characterization, v. 5I, n. 5, p. 315-27, Dec. 2003. http://dx.doi.org/10.1016/j.matchar.2004.01.006

13 GERMAN, R. M. Powder metallurgy science. Princeton: Metal Powder Industries Federation, 1984.

I4 GARTNER, T. M. Entwicklung eines Werkstoffes für hochbeanspruchte chirurgische Implantate auf der basis von Niob. 1989. 198 p. Tese (Doutorado) - Institut für Metallkunde, Montanuniversität Leoben, Leoben, Austria, 1989.

I5 GENNARI, U. et al. ODS-Niobium alloy. Its properties and applications. Modern Development in Powder Metallurgy, v.19, p.20I, Jun. 1988.

Recebido em: 07/0I/20II

Aceito em: 19/04/20II 